\title{
Material phase transformations due to shock wave loading in contact geometry
}

\author{
A. K. Sharma \\ Terminal Ballistics Research Laboratory, (TBRL) Ministry of Defence, \\ India
}

\begin{abstract}
When an explosive is detonated, it generates a transient shock wave in the medium. The shock wave energy turns out to be invigorating with insuperable power when used in a more convenable, advantageous and efficacious manner. This shock wave, when it propagates through the material, produces new phases/transformations. The monolithic materials thus formed have important technological applications. This paper describes the experimental technique used to synthesize the newer materials under shock wave loading and the characterization of post shock compacts by means of spectroscopic and other methods. Hexagonal boron nitride powder has been transformed into its cubic structure by loading the material by shock waves. X-ray analysis of the recovered samples with $\mathrm{I} / \mathrm{I}_{0}=8$ at $\mathrm{d}=1.808$ (angle $2 \varnothing=50.4^{0}$ ) has indicated complete conversion of h-BN to c-BN. Super alloy powders of IN 718 and EP $741 \mathrm{NP}$ of various chemical compositions and unique physical properties have been shock compressed. In EP 741 NP, the dendritic structure has been clearly observed in the centre with dendrites oriented in the radial direction, which happens to be the direction of heat flow. The structure needed for best results has been obtained. In IN 718, the dendritic structure within the particle is intact. The structure in the outer portion is better with satisfactory microstructure since the grain boundary has undergone solidification. Explosive compaction of a mechanical mixture of $80 \mathrm{Ni}-15 \mathrm{Fe}-5 \mathrm{Co}$ of grain size of about 30 nanometres has also been carried out for magnetic applications to study the effect of particle morphology. SEM analysis has indicated that the crystalline structure is intact in the shock-compressed specimens.
\end{abstract}

Keywords: dendritic structure, IN 718, EP $741 \mathrm{NP}, 80 \mathrm{Ni}-15 \mathrm{Fe}-5 \mathrm{Co}$, particle morphology, SEM analysis, X-ray analysis, diffractogram, mechanical mixture, microstructure. 


\section{Introduction}

The shock wave, when it propagates through materials, produces sudden changes of pressure and temperature, which ultimately result in the production of new phases/transformations. The compaction achieved by shock wave technology has contributed to the progress of material science by providing a way to study the shock induced phase transformations. The dynamic changes observed in the materials after the passage of shock waves have been the object of scientific curiosity all over the world. The transformations brought about by the shock waves are permanently retained in the materials after the passage of the shock pulse. The newer materials are produced by sudden densification/compaction of the powder by the shock wave pressure and heat. Densification of powders is due to the extremely rapid and intense deposition of energy over the grain boundaries. Solidification mainly occurs due to the transient pressure of the shock wave. Because of the short duration of the shock wave pulse, new monoliths are produced without changing the unique inherent material properties with limited grain growth.

In the literature, a number of scientists have reported shock consolidation of several rapidly solidifying powders to produce super hard materials, but still a number of problems remain to be investigated. A few of them are remaining cracks, weak inter particle bonding, inhomogeneities of consolidated material, clarity gradient and porosity at the core. Preparation and characterization of newer materials have attracted a wide range of fundamental and practical interest because of their interesting applications. Phase change due to the passage of shock wave, size reduction, morphology and compositions are the main concerns in applied material science. The selection of a technological material depends upon its cost, size, morphology, homogeneity and stoichiometry of the composition. There are also other applied aspects like increase of magnetic storage capacity with improved coercivity, retentivity and saturation magnetization, increased density with higher sharpness and hardness, the reduction of particle/grain size of the metal powder with potential utility for pyrophoric coatings and thin film deposition. Further investigations are needed to optimize the material applications in various devices such as memories, detectors, sensors, tuneable devices, switches etc. The optical band gap, refractive index, and the extinction coefficient are the most significant parameters.

The monolithic materials synthesized by the shock compression technique like cubic boron nitride, nickel based super alloys i.e. IN 718, EP $741 \mathrm{NP}$ and $\mathrm{Ni}-\mathrm{Fe}-\mathrm{Co}$ have numerous industrial applications. $\mathrm{C}-\mathrm{BN}$ is a very hard material with hardness ranking almost equal to diamond on Mohrs scale. This material is mostly used in cutting tool applications. Alloy Ni-Fe-Co is mainly used for ferromagnetic applications. The work reported in this paper is a part of the well-

defined experimental programme coupled with computer simulation studies to fabricate the aforesaid materials including refractory compounds, cermets and ceramic-metal composites. This technique is being further used as a predensification step before sintering. 


\section{Theoretical discussion}

Dynamic compaction by a shock wave is accompanied by high pressure acting on the material for a very short duration as compared to static compaction. The various physicochemical changes brought about by shock waves in the materials to synthesize the newer ones with unique properties and a number of industrial applications are difficult to achieve by static methods.

When an explosive is detonated, an axisymmetrical detonation wave propagates along the longitudinal direction of the undetonated part. Shock wave converges towards the axis and pressure grows steadily. The pressure generated accelerates the wall of the tube. This phenomenon has been depicted in fig. 1 .

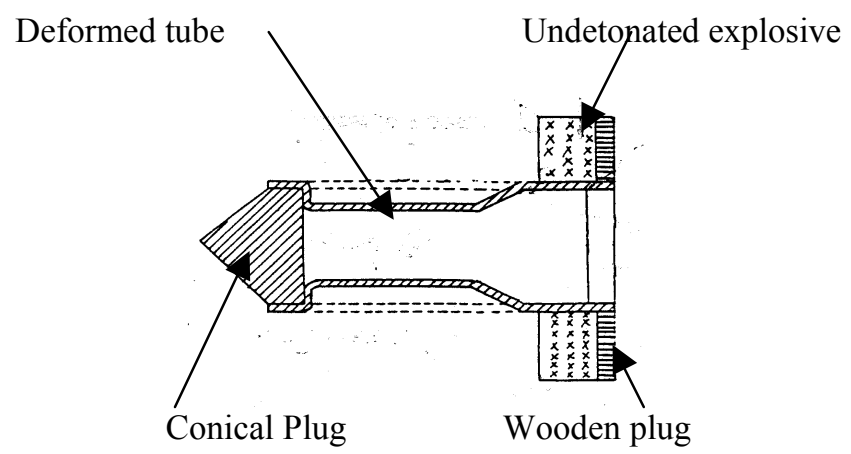

Figure 1: Shock compaction of metallic cylinder.

The propagation of shock waves in the powder takes place at a speed that is much smaller than the shock wave velocity in the corresponding solid cylinder. Therefore in the cylindrical arrangement of explosive compaction of the powder, oblique shock wave interaction is likely to occur. During propagation of shock wave in the cylindrical geometry, two opposing effects are decisive. The first one is the shock wave interaction of converging nature where the intensity increases towards the centre of the sample and the second one is the work performed on the powder primarily by plastic deformation of cutting or crushing of particles. Both effects in ideal cases are counterbalanced and uniform compaction over the cross section of the sample is achieved. Otherwise under or over compaction of the sample will result as reported by other workers $[1,2]$.

The densification and inter particle bonding mechanism which occur on a particulate scale during the dynamic/explosive compaction are extremely complex processes. In a transition from the powder state to a fully dense state during the passage of compaction wave, the particles must rapidly deform and flow to eliminate the void space and form stray inter particle bonds. It depends upon the generation of frictional and deformational heat, which softens the particle surface during the relative movement of the particles.

The explosive compaction zone is composed of a shock front followed by a zone of significant width in which powdered structure is transformed into a solid under the action of dynamic pressure generated by the explosive energy source. 
The shock wave energy is consumed in absorption and transition processes. The word absorption means the energy consumed by the particles and the transition means the energy consumed while imparting velocity to the particles. Greater the energy is absorbed the lesser is the energy transmitted to the subsequent neighbours.

A shock wave is a region of high pressure and temperature. The matter compressed by the shock wave is accompanied by a sudden rise in temperature and hence there is significant difference in the behaviour of solid and porous material. In shock loading of the porous material, the starting sample with specific volume is compressed by means of dynamic pressure to smaller volume. Most of the energy is dissipated by heat. A part of it is stored in the material in the form of lattice defect and distortion.

Increased explosive thickness increases the duration of the pressure pulse. Monolithic materials are produced by densification/compaction of the powder by applying pressure and heat. Densification of powders by shock compression utilizes the extremely rapid and intense deposition of energy over grain boundaries. Densification occurs mainly by pressure. Because of the short duration of the shock wave pulse, new monoliths are produced by densification of powders without changing their unique properties with limited grain growth.

\section{Preliminary work done}

An extensive literature survey has been carried out before the actual experimentation. Rigorous studies on the phase transformation/synthesis of newer materials have been undertaken after successfully compressing the powders of aluminium, iron and copper to almost $97-98 \%$ of their theoretical densities. To achieve this, a number of shock wave experiments have been carried out by changing the explosive to powder mass ratio and also the size of the compaction systems. One such compacted specimen has been shown in figure 2 .

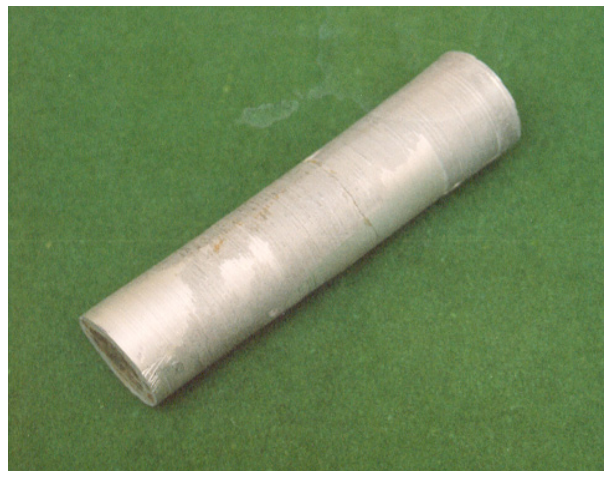

Figure 2: Compacted specimen. 


\section{Experimental work}

A number of research workers have used a variety of compaction systems for the powder compaction experiments $[3,4]$. The cylindrical compaction system is a metallic tube made of mild steel. It consists of a conical plug at the top and a plain plug at the bottom. Both the plugs are also fabricated out of mild steel.

The cylindrical ampoule is placed in a cylindrical plastic container having a wooden plug at the bottom. The space in between the metallic tube and Plastic container is filled with the explosive. A wooden plug having an electric detonator and booster covers the plastic container from the top. In order to carry out the experiment, the explosive filled compaction cylinder is placed in an earth pit for easy recovery of the compacted specimen. Fig. 3 shows the trial setup before the experiment whereas fig. 4 shows compacted cylinder recovered after the trial.

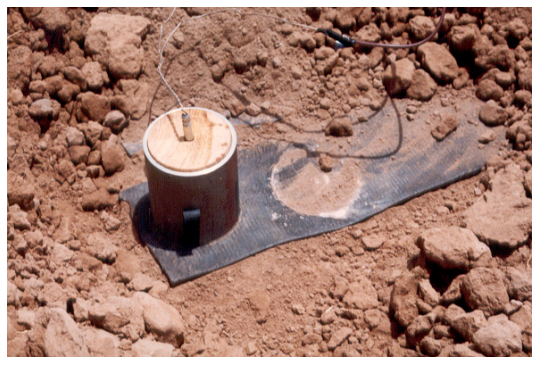

Figure 3: $\quad$ Trial setup.

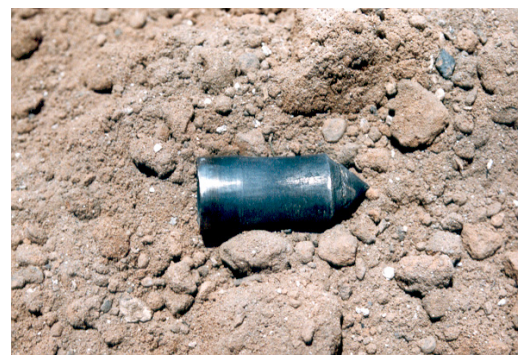

Figure 4: Compacted cylinder.

After carrying out the shock compaction trials using aluminium, iron and copper powders and standardizing the explosive to powder mass ratio, nature of explosive and shape and size of the compaction system, further rigorous studies on the phase transformation of Hexagonal Boron Nitride to Cubic Boron Nitride have been undertaken. The explosives such as Torpex 4A, RDX-TNT, PEK-1, Trimonite and ANFO have been used for carrying out the experiments. The Xray analysis of the shocked samples has been carried out. In these studies, X-ray lines of $\mathrm{c}-\mathrm{BN}$ with $\mathrm{I} / \mathrm{Io}=8$ have been observed. Presence of $\mathrm{h}-\mathrm{BN}$ has not been shown which indicates total conversion of h-BN to c-BN. An X- ray diffractogram of one of the shocked samples is shown in figure 5.

Shock compaction trials have also been carried out with IN 718 and EP 741 NP super alloy powders. The compacted samples have been retrieved from the compaction systems and the specimens are subjected to chemical composition and stress analysis studies. The report shows satisfactory compaction, as the porosity is not present.

The explosive compaction of nanocrystalline nickel base metal powder has been carried out. Alloy consists of $80 \%$ Nickel, 15\% Iron and 5\% Cobalt. This alloy is mainly used for making soft magnets. Before the shock compaction 


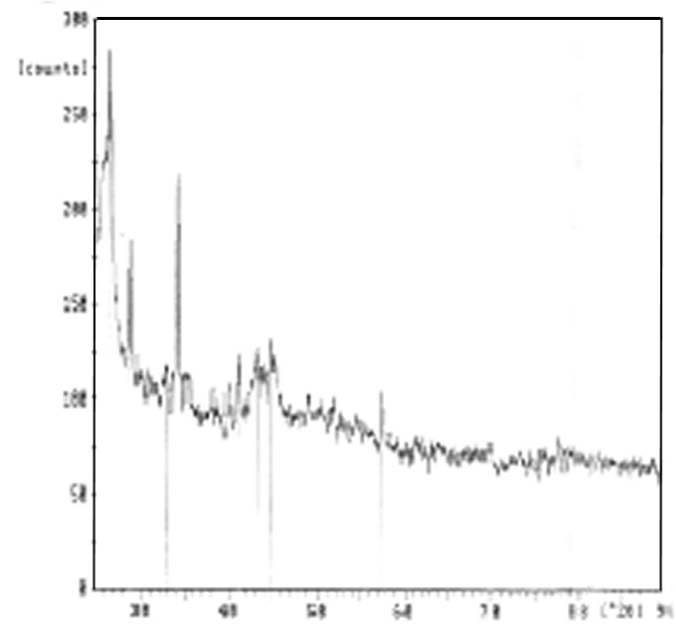

Figure 5: X-ray diffractogram.

experiments, mechanical alloying has been carried out by using a planetary ball mill. Powders are milled together for 125 hours in the Ball mill. Thereafter, the milled powder has been annealed at $500^{\circ} \mathrm{C}$ for different periods of time. XRD analysis for the grain size of the milled powder shows a 9.2 nanometer size.

\section{Results and discussion}

The compaction depends upon the ampoule material, tube wall thickness, quantity of explosive, velocity of detonation of explosive and also on the particle size and shape of the powder to be compacted. In the X-ray analysis of the recovered samples of the compacted boron nitride, the X-ray lines of c-BN have been clearly observed. The X-ray lines do not indicate the presence of h-BN. In order to achieve bulk production of c-BN, further shock transformation trials will be carried out in the near future using ampoules of larger size. The X- ray analysis results of the trial specimens have been shown in tables 1 and 2 .

One interesting aspect with copper powder and c-BN is that the X-ray lines of both the materials are identical and the only difference lies in the relative intensity $\left(\mathrm{I} / \mathrm{Io}\right.$ ) at $\mathrm{d}=1.808$ (Angle $2 \varnothing=50.4^{\circ}$ ) where it is 46 for $\mathrm{Cu}$ and 8 for $\mathrm{c}$ $\mathrm{BN}$. In the samples where both $\mathrm{c}-\mathrm{BN}$ and $\mathrm{Cu}$ powder are present, strong lines due to $\mathrm{Cu}$ with $\mathrm{I} / \mathrm{Io}=46$ overshadowed the weak lines due to $\mathrm{c}-\mathrm{BN}$ of $\mathrm{I} / \mathrm{Io}=8$ at the same $d$ value. One notable point in these experiments is that the presence of h-BN has not been indicated.

Super alloy powders such as IN 718 and EP 741 NP have been compacted. No porosity has been observed, however, some melting of the central portion has taken place. This problem is being overcome by carefully designing the shock wave experiments. The chemical composition and physical properties of the two alloys have been shown in tables 3, 4, 5 and 6 . 
Table 1: $\quad$ X-ray analysis results of trial specimens.

\begin{tabular}{|c|c|c|c|c|c|}
\hline $\begin{array}{l}\text { S. } \\
\text { No. }\end{array}$ & $\begin{array}{l}\text { Explosive } \\
\text { used }\end{array}$ & $\begin{array}{l}\text { Typical } \\
\text { 'd' values }\end{array}$ & $\begin{array}{l}\text { Relative } \\
\text { intensities }\end{array}$ & $\begin{array}{c}\text { Probable } \\
\text { Phases }\end{array}$ & $\begin{array}{l}\text { Unidentified } \\
\text { lines }\end{array}$ \\
\hline 1 & Torpex $-4 \mathrm{~A}$ & $\begin{array}{l}3.3336 \\
2.5433 \\
2.2943 \\
2.0945 \\
2.0315\end{array}$ & $\begin{array}{l}91.8 \\
100 \\
46.3 \\
17.4\end{array}$ & $\mathrm{Cu} / \mathrm{CBN}$ & $\begin{array}{l}2.5433 \\
2.2943\end{array}$ \\
\hline 2 & $\begin{array}{c}\text { RDX-TNT } \\
(60-40)\end{array}$ & $\begin{array}{l}2.5510 \\
3.3471 \\
2.0274\end{array}$ & $\begin{array}{c}100 \\
80 \\
41\end{array}$ & $\mathrm{Cu} / \mathrm{CBN}$ & 2.5510 \\
\hline 3 & PEK-I & $\begin{array}{l}2.0846 \\
2.0717 \\
1.8073 \\
1.7979\end{array}$ & $\begin{array}{l}100 \\
72.7 \\
44.1 \\
42.5\end{array}$ & $\begin{array}{l}\mathrm{Cu} / \mathrm{CBN} \\
\mathrm{Cu} / \mathrm{CBN} \\
\mathrm{Cu} / \mathrm{CBN} \\
\mathrm{Cu} / \mathrm{CBN}\end{array}$ & $\begin{array}{l}\text { All lines } \\
\text { identified }\end{array}$ \\
\hline 4 & Trimonite & $\begin{array}{l}2.0971 \\
1.8147 \\
1.2813 \\
1.0916\end{array}$ & $\begin{array}{c}100 \\
40 \\
26.6 \\
21.4\end{array}$ & $\begin{array}{l}\mathrm{Cu} / \mathrm{CBN} \\
\mathrm{Cu} / \mathrm{CBN} \\
\mathrm{Cu} / \mathrm{CBN} \\
\mathrm{Cu} / \mathrm{CBN}\end{array}$ & $\begin{array}{l}\text { Only other } \\
\text { lines } \\
\text { insignificant }\end{array}$ \\
\hline 5 & ANFO & $\begin{array}{l}2.0760 \\
1.8003 \\
1.2754\end{array}$ & $\begin{array}{l}100 \\
39.5 \\
22.9\end{array}$ & $\begin{array}{l}\mathrm{Cu} / \mathrm{CBN} \\
\mathrm{Cu} / \mathrm{CBN} \\
\mathrm{Cu} / \mathrm{CBN}\end{array}$ & $\begin{array}{l}\text { Two other } \\
\text { lines } \\
\text { insignificant }\end{array}$ \\
\hline 6 & ANFO & $\begin{array}{l}2.3349 \\
2.0760 \\
2.0248 \\
1.8016 \\
1.2790 \\
1.2757\end{array}$ & $\begin{array}{c}13 \\
100 \\
14.4 \\
41.8 \\
24.2 \\
27.1\end{array}$ & $\begin{array}{l}\mathrm{Cu} / \mathrm{CBN} \\
\mathrm{Cu} / \mathrm{CBN} \\
\mathrm{Cu} / \mathrm{CBN} \\
\mathrm{Cu} / \mathrm{CBN} \\
\mathrm{Cu} / \mathrm{CBN}\end{array}$ & $\begin{array}{l}\text { Two other } \\
\text { lines } \\
\text { insignificant }\end{array}$ \\
\hline 7 & Trimonite & $\begin{array}{l}2.0817 \\
1.8036 \\
1.2767\end{array}$ & $\begin{array}{c}100 \\
34 \\
17.1\end{array}$ & $\begin{array}{l}\mathrm{Cu} / \mathrm{CBN} \\
\mathrm{Cu} / \mathrm{CBN} \\
\mathrm{Cu} / \mathrm{CBN}\end{array}$ & $\begin{array}{l}\text { One other } \\
\text { line } \\
\text { insignificant }\end{array}$ \\
\hline 8 & PEK-I & $\begin{array}{l}2.0742 \\
2.0547 \\
2.0367 \\
1.7970 \\
1.7816\end{array}$ & $\begin{array}{c}100 \\
75 \\
43.4 \\
49 \\
36.7\end{array}$ & $\begin{array}{l}\mathrm{Cu} / \mathrm{CBN} \\
\mathrm{Cu} / \mathrm{CBN} \\
\mathrm{Cu} / \mathrm{CBN} \\
\mathrm{Cu} / \mathrm{CBN} \\
\mathrm{Cu} / \mathrm{CBN}\end{array}$ & \\
\hline
\end{tabular}


Table 2: $\quad \mathrm{X}$-ray analysis results of $\mathrm{c}-\mathrm{BN}$ and copper.

\begin{tabular}{|c|c|c|c|c|c|}
\hline \multicolumn{2}{|c|}{ Copper } & \multicolumn{3}{c|}{ CBN } \\
\hline $\mathrm{dA}$ & $\mathrm{I} / \mathrm{Io}$ & $\mathrm{hkl}$ & $\mathrm{dA}$ & $\mathrm{I} / \mathrm{Io}$ & $\mathrm{hkl}$ \\
\hline 2.088 & 100 & 111 & 2.088 & 100 & 111 \\
\hline 1.808 & 46 & 200 & 1.808 & 5 & 200 \\
1.278 & 20 & 220 & 1.2785 & 24 & 220 \\
\hline 1.0900 & 17 & 311 & 1.0901 & 8 & 311 \\
\hline 1.0436 & 5 & 222 & & & \\
\hline 0.9038 & 3 & 400 & 0.9039 & 2 & 400 \\
0.8293 & 9 & 331 & 0.8296 & 3 & 331 \\
\hline 0.8033 & 8 & 420 & & & \\
\hline
\end{tabular}

Table 3: $\quad$ Chemical composition of EP 741 NP, Wt. \%.

\begin{tabular}{|c|c|c|}
\hline Element & Powder sample & Specification as per VILS Moscow Russia \\
\hline $\mathrm{Co}$ & 15.6 & $15-16.5$ \\
\hline $\mathrm{Cr}$ & 8.8 & $8-10$ \\
\hline $\mathrm{MO}$ & 4.24 & $3.5-4.2$ \\
\hline $\mathrm{Al}$ & 5.6 & $4.65-5.25$ \\
\hline $\mathrm{Ti}$ & 1.64 & $1.6-2.0$ \\
\hline $\mathrm{W}$ & 5.1 & $5.2-5.9$ \\
\hline $\mathrm{Nb}$ & 2.4 & $2.4-2.8$ \\
\hline $\mathrm{Hf}$ & 0.27 & $0.1-0.4$ \\
\hline $\mathrm{B}$ & 0.02 & $0.02-0.06$ \\
\hline $\mathrm{C}$ & 0.03 & $0.02-0.06$ \\
\hline $\mathrm{O}$ & $60 \mathrm{ppm}$ & $60 \mathrm{ppm}$ \\
\hline $\mathrm{Ni}$ & Balance & Balance \\
\hline
\end{tabular}

Table 4: $\quad$ Physical properties of EP 741 NP produced by PREP technique.

\begin{tabular}{|c|c|}
\hline Particle shape & Spherical \\
\hline Mean particle size & 70 micron (By sleeve analysis) \\
\hline Apparent density & $5.0 \mathrm{gm} / \mathrm{cc}(61 \%$ of theoretical value $)$ \\
\hline Tap density & $5.4 \mathrm{gm} / \mathrm{cc}(66 \%$ of theoretical value $)$ \\
\hline Flow rate & $13 \mathrm{sec} / 50 \mathrm{gms}$ \\
\hline
\end{tabular}

In EP $741 \mathrm{NP}$, the dendritic structure has been clearly observed in the centre with dendrites oriented in the radial direction that also happens to be the direction of heat flow. This type of the structure is required for the best result. In IN 718, the dendritic structure with in the particle is intact. The structure in the outer portion is better with satisfactory microstructure since the grain boundary has undergone solidification. Successful compaction of nanocrystalline $\mathrm{Ni}-\mathrm{Fe}-\mathrm{Co}$ metal powder has been carried out by using ANFO explosive and $90 \%$ of the theoretical density has been achieved. SEM analysis of the milled powder shows 
that the particles are flaky rather than spherical and their shape is irregular. TEM analysis indicates that the grain boundaries are not present and the internal structure is a homogeneous solid. SAD pattern shows mix-ring-spots combination but predominantly the ring pattern indicates crystallinity with some degree of amorphous phase due to large number of grain boundaries. Intact compacted sample is obtained after machining the outer shell.

Table 5: $\quad$ Chemical composition of IN 718, Wt. \%.

\begin{tabular}{|c|c|c|}
\hline Element & $\begin{array}{c}\text { Powder sample } \\
\text { (Gas atomized) }\end{array}$ & $\begin{array}{c}\text { Specification as per } \\
\text { AMS: } 5663\end{array}$ \\
\hline $\mathrm{Cr}$ & 19.6 & $17-21$ \\
\hline $\mathrm{Fe}$ & 18.9 & $16-20$ \\
\hline $\mathrm{Nb}$ & 4.7 & $4.75-5.5$ \\
\hline $\mathrm{Mo}$ & 3.1 & $2.8-3.3$ \\
\hline $\mathrm{Al}$ & 0.8 & $0.2-0.8$ \\
\hline $\mathrm{Ti}$ & 0.5 & $0.65-1.15$ \\
\hline $\mathrm{C}$ & 0.03 & 0.08 max. \\
\hline $\mathrm{O}$ & $275 \mathrm{ppm}$ & --- \\
\hline $\mathrm{Ni}$ & Balance & Balance \\
\hline
\end{tabular}

Table 6: $\quad$ Physical properties of IN 718 produced by gas atomised technique.

\begin{tabular}{|c|c|}
\hline Particle shape & Spherical \\
\hline Particle size & Mesh size \\
distribution & (In micron): $(-106+75) \quad(-75+63) \quad(-63+53)$ \\
& $\begin{array}{c}(-53+37)(<37) \\
\end{array}$ \\
& Wt. $(\%): 10.2 \quad 8.5 \quad 17.7$ \\
& $27.7 \quad 35.9$ \\
\hline Mean particle size & $50 \mathrm{micron}$ (By sieve analysis) \\
\hline Apparent density & $4.18 \mathrm{gm} / \mathrm{cc}(51 \%$ of theoretical value $)$ \\
\hline Tap density & $5.17 \mathrm{gm} / \mathrm{cc}(63 \%$ of theoretical value $)$ \\
\hline Flow rate & $20 \mathrm{sec} / 50$ gms \\
\hline
\end{tabular}

Table 7: $\quad$ Physical properties of Ni-Fe-Co milled powder.

\begin{tabular}{|c|c|}
\hline Particle shape & Flakes form (irregular) \\
\hline Average particle size & $6 \mathrm{micron}$ \\
\hline Mean apparent density & $1.6197 \mathrm{gm} / \mathrm{cc}$ \\
\hline Mean Tap density & $2.5247 \mathrm{gm} / \mathrm{cc}$ \\
\hline
\end{tabular}

In another experiment in which trimonite is the explosive, $89 \%$ of the theoretical density has been achieved. The desired crystalline structure is intact in the shock compacted samples. However, to achieve higher densities further shock trials will be carried out in the near future. The physical properties of the nanocrystalline nickel powder have been shown in table 7 . 


\section{Acknowledgements}

The author is grateful to the Director TBRL for his encouragement and permission to present this work. The author also expresses his sincere thanks to all concerned in his working group at TBRL, CGCRI Kolkata and DMRL Hyderabad for their assistance in carrying out experimental trials, X-ray diffraction and stress analysis studies respectively.

\section{References}

[1] Petrie, M.W. \& Page, N.W., An equation of state for shock loaded powders, J. Appl. Phys. 69(6), pp. 3517-3524, 1991.

[2] Dijken, D.K. \& De Hosson, J. Th. M., Shock wave equation of state of powder material, J. Appl. Phys. 75(2), pp. 809-813, 1994.

[3] Yamada, Kenjiro, Boron carbide particles formed from an amorphous boron/graphite powder mixture using a shock wave technique, J. Am. Ceram. Soc. 79(4), pp. 1113-1116, 1996.

[4] Yamada, Kenjiro, Shock synthesis of a graphitic boron - carbon-nitrogen system, J. Am. Ceram. Soc. 81 (7), pp. 1941-1944, 1998. 